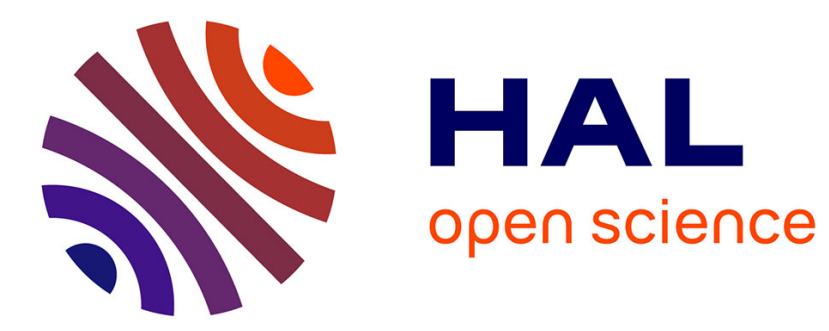

\title{
Risk and Sustainability: Assessing Fishery Management Strategies
}

\author{
V Martinet, J Peña-Torres, Michel de Lara, Hector Ramirez Cabrera
}

\section{To cite this version:}

V Martinet, J Peña-Torres, Michel de Lara, Hector Ramirez Cabrera. Risk and Sustainability: Assessing Fishery Management Strategies. Environmental and Resource Economics, 2014, 64 (4), pp.1-34. 10.1007/s10640-015-9894-0 . hal-01096439

\section{HAL Id: hal-01096439 \\ https://hal.inria.fr/hal-01096439}

Submitted on 17 Dec 2014

HAL is a multi-disciplinary open access archive for the deposit and dissemination of scientific research documents, whether they are published or not. The documents may come from teaching and research institutions in France or abroad, or from public or private research centers.
L'archive ouverte pluridisciplinaire HAL, est destinée au dépôt et à la diffusion de documents scientifiques de niveau recherche, publiés ou non, émanant des établissements d'enseignement et de recherche français ou étrangers, des laboratoires publics ou privés. 


\title{
Risk and Sustainability: Assessing Fishery Management Strategies
}

\author{
V. Martinet, J. Peña-Torresł M. de Lara ${ }^{\ddagger}$ and H. Ramírez C. ${ }^{\S}$
}

December 17, 2014

\begin{abstract}
We develop a theoretical framework to assess the sustainability of fishery management strategies, when the bioeconomic dynamics are marked by uncertainty and several conflicting objectives have to be accounted for. Stochastic viability ranks management strategies according to their probability to sustain economic and ecological outcomes over time. The approach is extended to build stochastic sustainable production possibility frontiers representing the trade-offs between sustainability objectives at any risk level, given the current state of the fishery. This framework is applied to a Chilean fishery faced with El Niño uncertainty. We study the viability of effort and quota strategies when catch and biomass levels have to be sustained. We show that i) for these sustainability objectives, whatever the level of the outcomes to be sustained, quota-based management results in a better viability probability than effort-based management, and ii) the fishery's historical quota levels were not sustainable given the stock levels in the early 2000s.
\end{abstract}

Keywords: sustainability, risk, fishery economics and management, stochastic viability.

${ }^{*}$ Corresponding author. INRA, UMR210 Economie Publique, F-78850 Thiverval-Grignon, France. vincent.martinet@grignon.inra.fr

${ }^{\dagger}$ Peña \& Sanchez Consultores Ltda, La Peninsula 11296, Las Condes, Santiago, Chile. julioalept@gmail.com

¥Université Paris-Est, Cermics, France. delara@cermics.enpc.fr

$\S$ Departamento de Ingeniería Matemática, Centro de Modelamiento Matemático (CNRS UMI 2807), FCFM, Universidad de Chile, Santiago, Chile. hramirez@dim.uchile.cl 


\section{Introduction}

The analysis in this paper originates in real concerns related to the management of Chilean fisheries. The jack-mackerel fishery is being challenged by uncertain El Niño cycles, which increase uncertainty about the availability of the resource (Barber and Chavez, 1983), making management of the fishery more difficult (Costello et al., 1998). ${ }^{1}$ In addition to the usual objective of maximizing profits, current management is aimed at avoiding stock collapse. Sustainable resource management requires a framework that takes account of both economic and ecological objectives under risk and over time.

The standard economic approach to assessing the performance of fishery management strategies relies on the expected discounted utility framework (Clark and Kirkwood, 1986; Reed, 1979; Sethi et al., 2005). This approach has the great advantage of defining a unique value, the expected discounted utility of harvesting, which characterizes optimal strategies and ranks alternative management strategies. However, it has some practical limits when applied to sustainable resource management issues encompassing several dimensions and the concern for intergenerational equity. First, accounting for ecological objectives requires the definition of a multi-attribute Social Welfare Function (SWF) prior to the maximization problem. However, if uncertainties are pervasive and if the sustainability issues affect multiple and heterogeneous stakeholders, the task of agreeing on a common SWF can be extremely intricate. Second, the discounted utility framework allows for intertemporal compensation of good and bad outcomes for the system, which may raise intergenerational equity issues (particularly if the discount rate is positive).

In practice, fishery management strategies, often defined as simple "rules of thumb," are evaluated in so-called "multicriteria" frameworks (Geromont et al., 1999; De Oliveira and Butterworth, 2004; Kell et al., 2005; Smith et al., 2007). These methods are based on simulations and do not rely on an optimization framework. They provide no common metrics for conflicting (ecological and economic) objectives and risk. Therefore, they cannot rank alternative management strategies explicitly. Thus, there is a gap in resource management between theory and practice. Developing a practical framework based on solid theoretical grounds to assess the sustainability of fishery management

\footnotetext{
${ }^{1}$ In some extreme cases, recruitment uncertainties and management decisions have led to the collapse of important small pelagic stocks, such as the Peruvian anchovy in 1972-1973.
} 
strategies under risk is a challenging task.

This paper proposes a framework which accounts for conflicting sustainability issues and risk, and provides an explicitly ranking of alternative management strategies. This framework echoes the concept of stewardship ${ }^{2}$ which defines sustainable resource management as a strategy that sustains economic and ecological outcomes over time, corresponding to a "satisficing" objective à la Simon (1957). Technically, we build on the stochastic viability approach (De Lara and Doyen, 2008). Given a set of multidimensional indicators referring to economic or ecological outcomes, viability is defined as the ability to sustain the levels of these indicators above some thresholds characterizing sustainability objectives (e.g., minimal biomass, minimal profit). We assess fishery management strategies according to their probability of achieving these objectives jointly, and at all times, over the planning horizon.

While stochastic viability has been used in previous studies as a simulation tool to examine fishery management issues (e.g., Doyen et al., 2012), the present paper differs in two important respects, each of which constitutes theoretical novelty. First, we embed stochastic viability in a theoretical optimization framework with economic interpretations, defining a value function for our optimization problem. This value measures the ability to sustain several outcomes over time. Second, while in viability analysis the thresholds of the viability constraints are usually exogenously fixed parameters, we treat these sustainability thresholds as explicit arguments of our value function. This allows us to define and build stochastic sustainable production possibility frontiers which describe the necessary trade-offs between sustained levels of economic and ecological outcomes and risk. Such possibility sets depend on the current (over)exploitation status of the fishery.

Our framework does not rely on an a priori representation of social preferences but can be used to reveal some of these preferences. Defining actual sustainability thresholds amounts to determining what should be sustained over time (Martinet, 2012). This is a social choice problem which is not addressed explicitly here. It corresponds to a generalized, multidimensional maximin problem (Solow, 1974; Martinet, 2011), with low substitutability among sustainability issues, and strong aversion to intertemporal inequality on all sustainability dimensions. Stochastic sustainable production possibility frontiers can be used to inform the social choice of sustainability objectives

\footnotetext{
${ }^{2}$ As discussed in the Stern review for climatic change (Stern, 2006).
} 
in the fishery, and to reveal social preferences related to sustainability issues.

These theoretical novelties allow us to bridge the gap between the economic literature on optimal resource management under risk, and the practical-oriented literature on sustainable fisheries management. The viability probability provides a common metrics to aggregate the outcomes of the system with respect to the several sustainability dimensions. It can be used to rank alternative management strategies. Marginal analysis makes it possible to examine the trade-offs between sustained outcomes and risk. Thus, our approach is closer to economics than the usual multi-criteria fishery management approaches. It can be implemented if no SWF is available.

We illustrate the implications of our approach in the case of the (small pelagic) Chilean jack-mackerel fishery which is threatened by El Niño uncertainty. In particular, we compare effort-based (price-like) and quota-based (quantity-like) strategies for their ability to sustain both catch and biomass levels over time given current information on the resource stock. While the price versus quantity issue in relation to fisheries has been debated extensively from an economic point of view, to our knowledge, the analysis in this paper is the first attempt to examine this issue from a sustainable management perspective.

Section 2 highlights the differences between the fishery economics literature and the fishery management literature which were the motivation for our approach. Section 3 presents our theoretical framework to assess risk and sustainability and compare management strategies. In Section 4, we apply this framework to the Chilean jack-mackerel fishery case-study. Section 5 concludes by discussing the relevance of our results for practical fisheries management.

\section{$2 \quad$ Background and settings}

Optimality in fishery economics is usually defined as maximization of the expected discounted profit of the harvest. Depending on the type of uncertainty and economic specifications, optimal harvesting may correspond to very specific management strategies, and be hard to apply in practice. ${ }^{3}$ Moreover, in a sustainability context, manage-

\footnotetext{
${ }^{3}$ See Reed (1979); Clark and Kirkwood (1986); Sethi et al. (2005); Nøstbakken and Conrad (2007); Nøstbakken (2008); McCough et al. (2009). When responding to uncertain stock fluctuations, optimality may require strong yearly variations of the Total Allowable Catch (TAC), pulse-fishing (Da-Rocha
} 
ment objectives are often not limited to profit maximization. Ecosystem-Based Fishery Management is aimed at conserving resources and sustaining the socio-economic benefits from fishing (Cochrane, 2000; Pikkitch et al., 2004). This increases the number of objectives and stakeholders (Fletcher, 2005) with the result that fisheries are faced with unsustainable situations whenever one of these objectives is not met. Prioritizing social and economic objectives over ecological targets has been identified as an important reason for management failure in fisheries (Hilborn, 2007). Management procedures (MP) ${ }^{4}$ should be ranked according to their capacity to yield acceptable results with respect to all sustainability objectives while being robust to uncertainties (Charles, 1998).

Extending the economic optimization approach to account for ecological objectives is a delicate exercise. In theory, one could define a multi-attribute SWF that would fully characterize social preferences over the various dimensions of interest, prior to the optimization problem. However, stakeholders may be unable to agree on a SWF. This a form of "collective" bounded rationality results in the impossibility to define a continuous representation of preferences over payoffs across various dimensions and risks. An alternative option would be to add ecological constraints to the profit maximization problem. Note that setting the levels of these constraints is a social choice problem which should not be overlooked. In the deterministic case, the optimization problem provides the marginal cost of complying with the constraint. This information can be used in a back-and-forth process with stakeholders to adjust the constraints level and reveal preferences over economic and ecological outcomes. This feature is lost in the stochastic case ${ }^{5}$ where a theoretical and technical issue emerges, i.e., how to interpret and handle constraints under uncertainty. It is possible to "translate" the deterministic economic criterion into its expected value but it is more difficult to "translate" a constraint in stochastic terms. Requiring constraint satisfaction with probability one, i.e., that the optimal strategy satisfies the constraint in all possible states of the world, et al., 2013), and even fishery closure if the stock size is too small (Nøstbakken, 2006), whereas fishing industries favor stability of catches (Charles, 1998).

${ }^{4} \mathrm{~A} \mathrm{MP}$ is a set of rules which translates fishery data into a regulatory mechanism, such as TAC or maximum fishing effort (Butterworth et al., 1997). MPs have been developed (though not always implemented) for a number of fisheries since their development within the International Whaling Commission in the late 1980s (De Oliveira and Butterworth, 2004).

${ }^{5}$ It will be seen that our framework provides somewhat similar information to support the choice of sustainability constraints in the stochastic case. 
usually restricts decisions to the extent that the optimization problem loses its interest. Another possibility would be accepting a risk of constraint violation. This amounts to considering the performance of the system with respect to the ecological constraint, by providing a measure of the risk of violating it. There are then two outcomes for each strategy: the expected economic profit, and the ecological risk.

This last option, in fact, is close to the Management Strategy Evaluation (MSE) approach. ${ }^{6}$ MSE relies on simulations to compare the performance of given management strategies against the conflicting objectives of limiting risk to the resource, reducing TAC variation over time, and increasing average catches. The results are usually represented graphically, in a map of "mean catch - risk to the resource" (see, e.g., Smith et al., 2007). Fig. 1 displays the results for the Chilean jack-mackerel fishery. "Ideal" management strategies present low risk to the resource and high mean catches, and are depicted in the South-East of the figure. Since there is no common metrics between objectives, the two performances cannot be aggregated, and non-dominated strategies cannot be ranked. ${ }^{7}$

The problem lies mainly in the fact that the economic and ecological objectives are not treated in the same way: the former is to maximize an outcome while the latter is to satisfy a constraint. The economics approach to risk is usually to define preferences characterizing value (i.e., to aggregate economic and ecological outcomes in a SWF) and to account for risk by computing expectation of value. ${ }^{8}$ The MSE approach compares the expected economic value with the ecological risk (probability to overshoot a given ecological threshold). The ecological objective is defined separately from economic value, which makes it difficult to aggregate the two outcomes.

Thus, assessing the sustainability of resource management strategies under risk is difficult when there is no SWF describing the preferences related to different issues. To address this challenge, we propose a theoretical framework that reflects the concept

\footnotetext{
${ }^{6}$ Various scientific tools, mainly in "multicriteria" frameworks, have been developed to support sustainable fisheries management (Smith et al., 2007). MSE is the most developed (Butterworth et al., 1997; Charles, 1998; Geromont et al., 1999; Sainsbury et al., 2000; De Oliveira and Butterworth, 2004; Kell et al., 2005).

${ }^{7}$ Moreover, the MSE approach provides no information on the opportunity cost of the ecological constraint or the marginal gains from relaxing its level.

${ }^{8}$ For some types of utility functions, e.g., Constant Absolute Risk Aversion functions, preferences under risk may be represented by means of a linear function of expected (mean) profits and a simple proxy for risk such as variance of profits.
} 


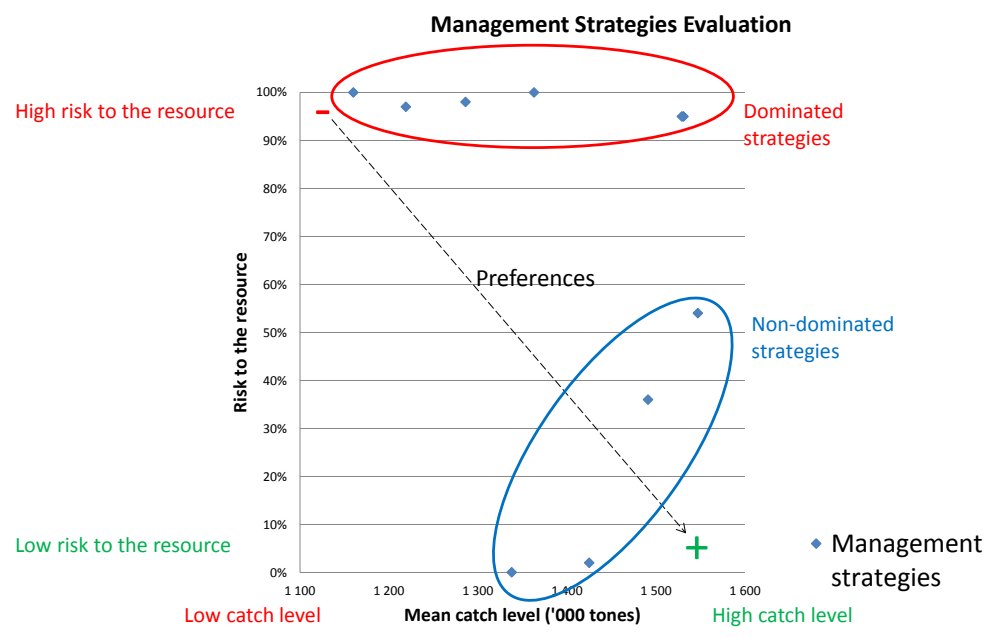

Figure 1: MSE for the Chilean Jack Mackerel fishery: performance of various management strategies in terms of risk to the resource (measured as the probability that the stock falls below $20 \%$ of the pre-exploitation spawning stock biomass) and expected mean annual catches (used as a proxy variable for the economic objective). Adapted from Yepes (2004).

of stewardship. We assume that intertemporal equity requires the economic and ecological performance of the system to be sustained over time. These conditions can be represented by constraints on (ecological and economic) indicators, which should be maintained above some thresholds at all times. This issue is addressed in a stochastic viability framework which defines the (maximal) probability of satisfying jointly several viability constraints over time in dynamic, uncertain models. Any management strategy satisfies these viability constraints with some probability. This viability probability provides a common metrics to assess and rank alternative strategies.

This approach treats all the relevant sustainability objectives as minimal outcomes to be sustained over time. Defining the viability thresholds as arguments of the stochastic viability value function, we build stochastic sustainable production possibility frontiers, which exhibit the necessary trade-offs between the targeted sustained outcomes and risk. These frontiers can be used in the social choice of sustainability objectives. 


\section{A metrics for risk and sustainability}

Let us formalize the decision problem in a general framework. The model and method described below are appropriate for setting up any stochastic viability analysis, and therefore can be applied to a variety of resource management situations or to environmental problems with stocks of pollutants. We provide examples based on the fisheries case.

\subsection{Modeling framework}

Dynamic system Consider a resource harvesting model, which accounts for dynamics, uncertainty and exploitation decisions. The model is described by the following discrete-time control dynamic system

$$
x(t+1)=G(t, x(t), c(t), \omega(t)), \quad t=t_{0}, \ldots, T-1, \quad x\left(t_{0}\right)=x_{0},
$$

where

- the time index $t$ is discrete, belonging to $\mathbb{T}=\left\{t_{0}, \ldots, T\right\} \subset \mathbb{N}$; the time period $\left[t, t+1\left[\right.\right.$ is a year for example; $t_{0}$ is the initial time ; $T$ is the finite time;

- the state vector $x(t) \in \mathbb{X} \subset \mathbb{R}^{n}$ could be a vector of abundance-at-age for one or for several species; It could also represent abundances at different spatial patches or include capital stocks (e.g., fishing vessels);

- the control vector $c(t) \in \mathbb{C} \subset \mathbb{R}^{p}$ could denote catches or harvesting effort;

- $\omega(t) \in \mathbb{W} \subset \mathbb{R}^{q}$ denotes a vector of uncertainty which affects the dynamics at time $t$ (e.g., recruitment or mortality uncertainties in a dynamic population model, climate fluctuations or trends, unknown technical progress, price uncertainty);

- $G: \mathbb{T} \times \mathbb{X} \times \mathbb{C} \times \mathbb{W} \rightarrow \mathbb{X}$ represents the dynamics of the system. It could be one of the numerous dynamic population models, such as logistic or age-class models; it could also include capital accumulation dynamics;

- $x_{0} \in \mathbb{X}$ is the given initial state for the initial time $t_{0}$. It is supposed to be known.

The notation $c(\cdot)$ means a control trajectory $c(\cdot)=\left(c\left(t_{0}\right), \ldots, c(T)\right)$ whereas $x(\cdot)=$ $\left(x\left(t_{0}\right), \ldots, x(T)\right)$ denotes a state trajectory. 
Probability distributions over scenarios A scenario is a sequence of uncertainty vectors denoted by $\omega(\cdot)=\left(\omega\left(t_{0}\right), \ldots, \omega(T-1)\right)$. We define the set of all possible scenarios as

$$
\Omega=\mathbb{W}^{T-t_{0}} .
$$

We assume that the set of scenarios $\Omega$ is equipped with a probability distribution $\mathbb{P}^{9}$ Formally, this probability $\mathbb{P}$ could be either an objective probability derived from a statistical model using real world data (as in our case study in Section 4), or a subjective probability representing the decision-maker's beliefs.

Decision rules and management strategies When uncertainties affect the dynamics, closed loop or feedback controls $\widehat{c}(t, x(t))$ accounting for the uncertain state evolution $x(t)$ display more adaptive properties than open-loop controls $c(t)$ depending only on time. A (state) feedback is a decision rule which assigns a control $c=\widehat{c}(t, x) \in \mathbb{C}$ to any state $x$ for any time $t$. Hereafter, we use the term (management) strategies to refer to feedback decision rules. The set of all possible strategies is denoted by $\mathcal{C}$.

\subsection{Stochastic Viability}

Sustainability objectives described with indicators and thresholds Consider $K$ real-valued functions $\mathcal{I}_{k}: \mathbb{T} \times \mathbb{X} \times \mathbb{C} \rightarrow \mathbb{R}$, for $k=1, \ldots, K$, which represent instantaneous indicators with economic or ecological meaning (e.g., profit, annual catches, Spawning Stock Biomass - SSB). Thresholds $\tau_{1} \in \mathbb{R}, \ldots, \tau_{K} \in \mathbb{R}$, measured in the same unit as the indicators (e.g., money, tons) define constraints formalizing sustainability objectives: ${ }^{10}$

$$
\mathcal{I}_{k}(t, x(t), c(t)) \geq \tau_{k}, \quad \forall k=1, \ldots, K, \quad \forall t=t_{0}, \ldots, T .
$$

In the viability framework, a trajectory that does not satisfy one (or more) of the constraints at some time is not viable. At a given time period, the violation of some of the sustainability constraints is not compensated by good outcomes in

\footnotetext{
${ }^{9}$ Technically, the probability $\mathbb{P}$ is defined over the Borel $\sigma$-algebra of $\Omega$. In what follows, we assume proper measurability assumptions for all the functions we consider.

${ }^{10}$ We consider sustainability "goods," for which an ad-hoc indicator is defined. This indicator is then constrained to be above a certain threshold. For "bads," such as pollution (e.g., $\mathrm{CO}_{2}$ concentration), one can take their negative value as an indicator.
} 
other sustainability dimensions. Violation of the sustainability constraints at some time periods is not compensated by good outcomes at other time periods. ${ }^{11}$ The requirement to satisfy all constraints at all times reflects the idea that sustainability has to encompass ecological and economic issues in an intergenerational equity perspective.

In a stochastic framework, it is generally impossible to satisfy the constraints for all scenarios $\omega(\cdot)$. We use the term viable scenarios to refer to the uncertainty scenarios where all viability constraints are satisfied at all times under a given strategy.

Viable scenarios associated with a management strategy For any management strategy $\widehat{c}$, initial state $x_{0}$, and initial time $t_{0}$, we define the set of viable scenarios as:

$$
\Omega_{\widehat{c}, t_{0}, x_{0}}=\left\{\begin{array}{l|l}
\omega(\cdot) \in \Omega & \begin{array}{l}
x\left(t_{0}\right)=x_{0} \\
x(t+1)=G(t, x(t), c(t), \omega(t)) \\
c(t)=\widehat{c}(t, x(t)) \\
\mathcal{I}_{k}(t, x(t), c(t)) \geq \tau_{k}, k=1, \ldots, K \\
t=t_{0}, \ldots, T
\end{array}
\end{array}\right\} .
$$

For a given strategy $\widehat{c}$ and a given scenario $\omega(\cdot)$, the dynamics (1) produces a state trajectory $x(\cdot)$ and a control trajectory $c(\cdot)$ once the strategy $c(t)=\widehat{c}(t, x(t))$ is applied. Therefore, a viable scenario $\omega(\cdot) \in \Omega_{\widehat{c}, t_{0}, x_{0}}$ is one where the state and control trajectory $(x(\cdot), c(\cdot))$ driven by the strategy $\widehat{c}$ satisfies the constraints $(3)$.

In the ideal case where a strategy $\widehat{c}$ exists such that $\Omega_{\widehat{c}, t_{0}, x_{0}}$ coincides with $\Omega$, viability can be achieved for all scenarios by applying this strategy. If this is not the case, since $\Omega$ is equipped with a probability $\mathbb{P}$, we can measure the likelihood that a strategy $\widehat{c}$ will meet the objectives by the probability of associated viable scenarios, $\mathbb{P}\left[\Omega_{\widehat{c}, t_{0}, x_{0}}\right]$, which is called the viability probability associated with the management strategy $\widehat{c}$, the initial time $t_{0}$, and the initial state $x_{0}$.

Management strategy assessment by stochastic viability For any given set of sustainability thresholds $\tau_{1}, \ldots, \tau_{K}$, a management strategy can be assessed by its

\footnotetext{
${ }^{11}$ For given sustainability thresholds, there are no trade-offs, either among sustainability issues or among time periods. All trade-offs occur when the thresholds are defined (Martinet, 2011, 2012). We emphasize how our framework can be used to support the definition of the thresholds.
} 
viability probability. To stress the dependency on thresholds, we introduce the notation

$$
\Pi\left(\widehat{c}, \boldsymbol{\tau}_{\mathbf{1}}, \ldots, \boldsymbol{\tau}_{\boldsymbol{K}}\right)=\mathbb{P}\left\{\begin{array}{l|l}
\omega(\cdot) \in \Omega & \begin{array}{l}
x\left(t_{0}\right)=x_{0} \\
x(t+1)=G(t, x(t), c(t), \omega(t)) \\
c(t)=\widehat{c}(t, x(t)) \\
\mathcal{I}_{k}(t, x(t), c(t)) \geq \boldsymbol{\tau}_{\boldsymbol{k}}, k=1, \ldots, K \\
t=t_{0}, \ldots, T
\end{array}
\end{array}\right\}
$$

This viability probability is a common metrics to evaluate the consistency of a given strategy and sustainability objectives. The higher this probability, the lower the risk of violating the sustainability constraints.

Note that, as in the case of expected discounted utility, stochastic viability analysis depends on the probability distribution $\mathbb{P}$. In particular, since we are dealing with intertemporal issues, we need to be cautious about how $\mathbb{P}$ captures temporal dependencies among uncertainties (e.g., independent random variables, Markov chains, or time series). Investigating the sensitivity of the results to the probability distribution is beyond the scope of this paper.

Ranking of management strategies The stochastic viability approach ranks strategies according to their viability probability. A management strategy $\widehat{c}$ is "more viable" than another strategy if the corresponding set of viable scenarios has a higher probability. A most viable strategy $\widehat{c}^{\star}\left(\tau_{1}, \ldots, \tau_{K}\right)$ is one that maximizes the viability probability $\Pi\left(\widehat{c}, \tau_{1}, \ldots, \tau_{K}\right)$ for a given set of sustainability thresholds $\tau_{1}, \ldots, \tau_{K}$ over all possible strategies $\widehat{c} \in \mathcal{C}$.

\subsection{Theoretical extension to the stochastic viability frame- work}

This paper is original in treating the viability thresholds as arguments of the viability probability. This defines a value function for our sustainability problem.

\section{A "value function" for sustained outcomes The maximal viability probability}

$$
\Pi^{\star}\left(\tau_{1}, \ldots, \tau_{K}\right)=\max _{\widehat{c} \in \mathcal{C}} \Pi\left(\widehat{c}, \tau_{1}, \ldots, \tau_{K}\right)
$$

is the highest probability that objectives $\left(\tau_{1}, \ldots, \tau_{K}\right)$ are sustained. It is the value function of the stochastic viability optimization problem. This value function depends 
on the threshold levels. We use this value function to describe the trade-offs among sustainability objectives.

Stochastic sustainable production possibility frontiers When the maximal viability probability function $\Pi^{\star}\left(\tau_{1}, \ldots, \tau_{K}\right)$ varies smoothly with respect to the threshold levels (as generally the case when the probability distribution $\mathbb{P}$ has a smooth density), the marginal variation of viability probability with respect to the threshold level $\tau_{k}$ is $\frac{\partial}{\partial \tau_{k}} \Pi^{\star}\left(\tau_{1}, \ldots, \tau_{K}\right)$. This represents the marginal cost, in terms of viability probability, of increasing the level of this constraint. It provides information on the difficulty of sustaining the corresponding outcome over time, given other sustainability objectives.

The value function (6) can be used to build stochastic sustainable production possibility frontiers exhibiting the trade-offs among sustained levels of outcomes and viability probability. In particular, for any confidence level $\pi \in[0,1]$, it is possible to define the threshold levels $\tau_{1}, \ldots, \tau_{K}$ at which $\Pi^{\star}\left(\tau_{1}, \ldots, \tau_{K}\right)=\pi$. The marginal rate of substitution between thresholds $\tau_{i}$ and $\tau_{j}$ along the corresponding iso-value viability probability curve is then defined by

$$
\frac{\partial \Pi^{\star}\left(\tau_{1}, \ldots, \tau_{K}\right) / \partial \tau_{i}}{\partial \Pi^{\star}\left(\tau_{1}, \ldots, \tau_{K}\right) / \partial \tau_{j}}=\frac{\partial \tau_{j}}{\partial \tau_{i} \Pi^{\star}\left(\tau_{1}, \ldots, \tau_{K}\right)=\pi}
$$

This rate measures the necessary trade-offs between the two sustainability objectives, at a given risk level, i.e., how much one objective must be reduced to increase the other without changing the viability probability.

Suboptimal cases Our framework can be used also if it is not possible to identify an optimal strategy (e.g., because it cannot be computed). In a second-best setting, it is possible to consider subsets of strategies $\tilde{\mathcal{C}} \subset \mathcal{C}$ and define the associated (sub-optimal) viability probability:

$$
\tilde{\Pi}\left(\tau_{1}, \ldots, \tau_{K}\right)=\max _{\widehat{c} \in \tilde{\mathcal{C}}} \Pi\left(\widehat{c}, \tau_{1}, \ldots, \tau_{K}\right)
$$

While we recognize the pitfalls involved in such comparisons with an ad hoc reduced number of management strategies, this provides an analytical tool for comparing and ranking realistic management strategies according to a well-defined yardstick that is based on the corresponding viability probability. This ranking exercise could be used to inform stakeholders in the discussion of given strategies with management relevance 
(e.g., effort-based or quota-based strategies). The viability probability of the strategies then provides a metrics for ranking them. In particular, by letting sustainability thresholds vary, it is possible to define within which range of sustainability threshold levels one type of strategy performs better than another.

\section{A case-study: the Chilean jack-mackerel fishery}

We model the Chilean jack-mackerel fishery and use it as a case-study to apply the stochastic viability approach, and in particular, the theoretical extensions described in the previous section.

\subsection{Description of the fishery and management issues}

The jack-mackerel fishery has been the largest fishery in Chile for many years, in terms of both annual catch and economic value. ${ }^{12}$ Like other small pelagic stocks, jackmackerel stocks are affected by the recurrences of El Niño in uncertain cycles. Since the late 1990s, the fishery has been managed under a yearly-defined TAC and closed entry, taking particular account of the stability of catch levels over time. Additionally, since the mid-2000s, the jack-mackerel fishery has pioneered (in Chile) the inclusion of biology-related risk indicators in its management practices. ${ }^{13}$ These indicators provide additional information for the policy decision making process, with the underlying objective of capping biological (collapse) risk; however, they are not applied within a formal framework allowing trade off of this risk against measures of economic return. Despite its management strategies, the Chilean jack-mackerel fishery is currently in crisis.

Historical data on the jack-mackerel fishery are provided in the Appendix, Table 1. Year 2002 appears to be a turning point for two reasons: i) biomass levels were half the peak in the late 1980s, and recruitment was half the levels in the previous five years, ${ }^{14}$

\footnotetext{
${ }^{12}$ Annual catch peaked at 4.4 million tons in 1995, and value generation was around US $\$ 400$ millions of yearly sales until the 2010s.

${ }^{13}$ SUBPESCA, the regulatory body for Chilean fisheries, started assessing the probabilities of reducing the SSB, relative to a historical base level, for various exogenously defined quota levels (see SUBPESCA (2004, p. 26-27) and IFOP (2006, p. 33-39)).

${ }^{14}$ This was probably related to lagged effects from the very strong 1997/98 El Niño event (Peña Torres et al., 2007, 2014).
} 
ii) the spatial distribution of the stock changed (Peña Torres et al., 2014), moving part of the stock outside Chile's Exclusive Economic Zone (EEZ), which triggered the re-opening of an international-waters jack mackerel fishery (see Table 1 column (2)).

Despite the changes in the biology of the stock and its exploitation pattern after 2002, the Chilean fisheries regulator decided to keep TAC levels almost constant for the Chilean fleet targeting jack mackerel within and beyond the Chilean EEZ over the period 2000 - 2010 (see Table 1 column (3)). Biomass levels began a monotonic decline, from $48 \%$ of virgin $S S B\left(S S B_{\text {virg }}\right)^{15}$ in 2002 , down to $16 \%$ in 2012 . The management strategy changed only in 2011, when the TAC fell by $76 \%$ between 2010 and 2011, from 1,300 to $315 \mathrm{k}$-tons; in 2013 it was around $250 \mathrm{k}$-tons.

Thus, the period 2002-2011 is of particular interest for this fishery. It covers 10 years of management, which is the management horizon used by IFOP. It starts with a change in the biology of the stock, and ends with a collapse of the fishery and a change in management strategy. We model this period over a 10 year horizon, taking 2002 as the initial year of our simulation.

This modeling exercise has two objectives. First, we assess the sustainability of some management strategies and compare them to the fishery's historical evolution. Second, we build stochastic sustainable production possibility frontiers for the fishery given the 2002 stock. This allows us to determine the levels of sustainable outcomes, given the stock at the beginning of the period.

\subsection{Bioeconomic model ${ }^{16}$}

Biology: We describe the dynamics of the Chilean jack-mackerel stock using an ageclass model (Quinn and Deriso, 1999; Tahvonen, 2009) with a Ricker recruitment function. ${ }^{17}$ Time is measured in years. The initial year is $t_{0}=2002$ and the final year is $T=2011$. The time index $t=t_{0}, t_{0}+1, \ldots, T$ represents the beginning of year $t$. Let $A=12$ denote the maximum age group, and $a \in\{1, \ldots, A\}$ be an age class index, all expressed in years. The vector $N=\left(N_{a}\right)_{a=1, \ldots, A} \in \mathbb{R}_{+}^{A}$ is a vector of abundance-at-age:

\footnotetext{
${ }^{15}$ The Chilean fishery research institute (IFOP) estimated this parameter at $S S B_{\text {virg }}=14.3$ million tons. It uses the maximum recorded SSB for this fishery (in 1988) as a proxy.

${ }^{16}$ Data, parameters and computational details are described in the Appendix.

${ }^{17}$ The Ricker model is frequently used for species with highly fluctuating recruitment, involving high fecundity as well as high natural mortality rates (Begon and Mortimer, 1986). These two features characterize small pelagic species such as jack-mackerel.
} 
for $a=1, \ldots, A-1, N_{a}(t)$ is the number of individuals aged between $a-1$ and $a$ at the beginning of year $t ; N_{A}(t)$ is the number of individuals older than $A-1$.

The dynamics of the form of eq. (1) is provided in the Appendix (eqs. 11, 13 and 14). The state vector $\left(A+1\right.$-dimensional) is $x(t)=\left(N_{1}(t), \ldots, N_{A}(t), \operatorname{SSB}(N(t-1))\right)$, where the $S S B$ is defined by eq. (13). Fishing activity is represented by a fishing effort multiplier $\lambda(t)$, assumed to be applied continuously during the period $t$. The control then is $c(t)=\lambda(t)$. Total annual catches $Y$, measured in million tons, are given by the Baranov catch equation (eq. 12).

El Niño cycles model: The El Niño phenomenon is the result of a wide and complex system of climatic fluctuations between the ocean and the atmosphere, whose frequency and intensity are uncertain. We simulate the uncertain El Niño cycles using a model with a periodic part and an error term, to produce a cycle with random shocks. Details are provided in the Appendix.

Economics: We make the following standard economic assumptions (Reed, 1979; Clark and Kirkwood, 1986; Clark, 1990).

(a1) Demand is infinitely elastic. The harvest from this fishery goes mainly to fish meal, a commodity with high demand substitution. Therefore, this fishery is essentially a price-taking industry, and we assume that any unit harvested is sold for a given, exogenous price.

(a2) Per unit harvest costs are not dependent on harvest volume and vary with population abundance. These costs increase as the size of the population decreases. This is equivalent to assuming that fishing effort has a constant unit cost, and that Catches Per Unit of Effort (CPUE) decrease if the stock decreases.

Under these assumptions, since the CPUE decreases when stock size falls, there is a minimal stock size below which the marginal cost of fishing effort (which is constant) is higher than the marginal revenue from fishing effort. We assume that no extra fishing effort occurs once the marginal profit is nil. This implies that fishing effort has an upper bound.

For fisheries satisfying these assumptions, price and cost levels do not have a qualitative effect on our results. The regulator usually observes prices but fishing costs 
are private information and depend on factors specific to fishing vessels. Thus, profit functions are difficult to estimate without strong assumptions related to fleet homogeneity. In practice, the most frequent approach is to use catches to proxy for revenue, and fishing effort related variables to proxy for costs. Since in practice quotas are defined in quantity terms, it is reasonable to focus on harvest quantities and fishing effort to proxy for revenue and fishing costs. This assumption is in line with, for example, Reed (1979), Clark and Kirkwood (1986) and Sethi et al. (2005), where the expected discounted sum of harvest rather than the expected discounted sum of profit is maximized.

\subsection{Economic and biological sustainability objectives}

We consider the ecological objective of sustaining the $S S B$ above some limit defined as a percentage of $S S B_{\text {virg. }}$. This objective is formalized by the constraint

$$
\frac{S S B(N(t))}{S S B_{\text {virg }}} \geq p, \quad \forall t=t_{0}, t_{0}+1, \ldots, T,
$$

where the threshold $p$ denotes the desired minimum percentage of $S S B_{\text {virg }}$ to be preserved over time. In our analysis, $p \in[0.15 ; 0.25]$, which means that the constraint on the $S S B(N(t))$ varies between $15 \%$ and $25 \%$ of $S S B_{\text {virg }} \cdot{ }^{18}$ The constraint (9) cor-

responds to the following indicator and threshold: $\mathcal{I}_{1}(t, x(t), c(t))=\frac{S S B(N(t))}{S S B_{\text {virg }}}$ and $\tau_{1}=p$.

We also consider the socio-economic objective of sustaining the annual yield above a level $y_{\min }$ :

$$
Y(N(t), \lambda(t)) \geq y_{\min }, \quad \forall t=t_{0}, t_{0}+1, \ldots, T .
$$

The minimum level of landings to be sustained over time $\left(y_{\min }\right)$ can take values from 0 to 2 million tons, corresponding to catch levels observed in this fishery in the first decade of 2000. The constraint (10) corresponds to the following indicator and threshold: $\mathcal{I}_{2}(t, x, c)=Y(N, \lambda)$ and $\tau_{2}=y_{\text {min }}$. This constraint presumes that the fishery regulator aims at maintaining a minimum level of fishing activity, due possibly to socioeconomic considerations.

\footnotetext{
${ }^{18}$ In the case of South African small pelagic fisheries (sardines and anchovies) in the late 1980s and early 1990s, the fishery regulator considered $p=0.2$ when applying such biological criteria (Butterworth and Bergh, 1997).
} 


\subsection{Viability assessment of management strategies}

Using the stochastic viability approach, we compare management strategies for the Chilean jack-mackerel fishery.

Although optimization approaches provide a description of "optimal" management strategies, many fisheries are managed using much simpler tools. ${ }^{19}$ Constant fishing effort and constant quotas are two basic management strategies. The former approach, known also as fixed fishing mortality, is based on advice from biologists and results in fluctuating harvests as stocks fluctuate. The optimal strategy may be neither of these approaches (Hannesson and Steinshamn, 1991) but these rules of thumb are still frequently proposed (and indeed used sometimes) as potential management strategies in some fisheries. In the 1980s and 1990s, Chilean fisheries were de facto managed under a constant effort rule (frozen maximum effort). In 2000, a quota system was applied with a posteriori very small changes to TAC levels from year to year. For example, the management strategy applied to the jack-mackerel fishery over the studied period resembles a constant quota-type policy (see Table 1).

We focus on two different types of strategies: constant fishing effort and constant quota, both stationary over a fixed period of 10 years.

A constant effort strategy (CES) is a strategy defined by a constant effort ${ }^{20} \lambda(t, N)=$ $\bar{\lambda}$. The set of all possible $\mathrm{CES}$ is denoted by $\tilde{\mathcal{C}}^{E} \subset \mathcal{C}$.

A constant quota strategy (CQS) is a strategy implicitly defined by a constant quota $\bar{Y}$. The associated fishing effort multiplier $\widehat{\lambda}(t, N)$ is such that $Y(N, \widehat{\lambda}(t, N))=\bar{Y}$ whenever this is possible, i.e., if the corresponding effort level is below the upper bound for fishing effort. If it is not, the actual catch level may be lower than the quota. The set of all possible CQS is denoted by $\tilde{\mathcal{C}}^{Q} \subset \mathcal{C}$.

For each subset of strategies $\tilde{\mathcal{C}}^{E}$ and $\tilde{\mathcal{C}}^{Q}$, we compute the associated maximal viability probability as a function of the two sustainability thresholds: For each pair $\left(p, y_{\text {min }}\right) \in[0 ; 2] \times[0.15 ; 0.25]$ of economic and ecological thresholds, ${ }^{21}$ we define, within each subset of management strategies, the level of the policy instrument which re-

\footnotetext{
${ }^{19}$ E.g., Singh et al. (2006) describe the Alaskan Pacific halibut stock as being managed by setting the yearly harvest as a fixed fraction of the exploitation biomass; this constant harvest rate rule is shown to smooth catches over time more than the optimal policy.

${ }^{20} \mathrm{In}$ our model, fishing mortality is proportional to fishing effort if the fishing technology is constant. Thus, a CES is identical to the constant fishing mortality strategy depicted here.

${ }^{21}$ Technically, we discretize the intervals.
} 
sults in the highest viability probability (best constant quota, or best constant effort, to sustain the given objectives). The viability probability is approximated by a frequency given by Monte Carlo simulations (over 1, 000 simulations). We compute a 95\% confidence interval for its value. These viability probabilities are displayed in Fig. 2. For each strategy (left-hand panel for CES and right hand-side panel for CQS), we draw iso-probability curves over the two thresholds, for the levels of maximal viability probability $\{0 ; 0.1 ; 0.5 ; 0.9 ; 0.99 ; 1\}$. Both graphics in Fig. 2 represent the "stochastic
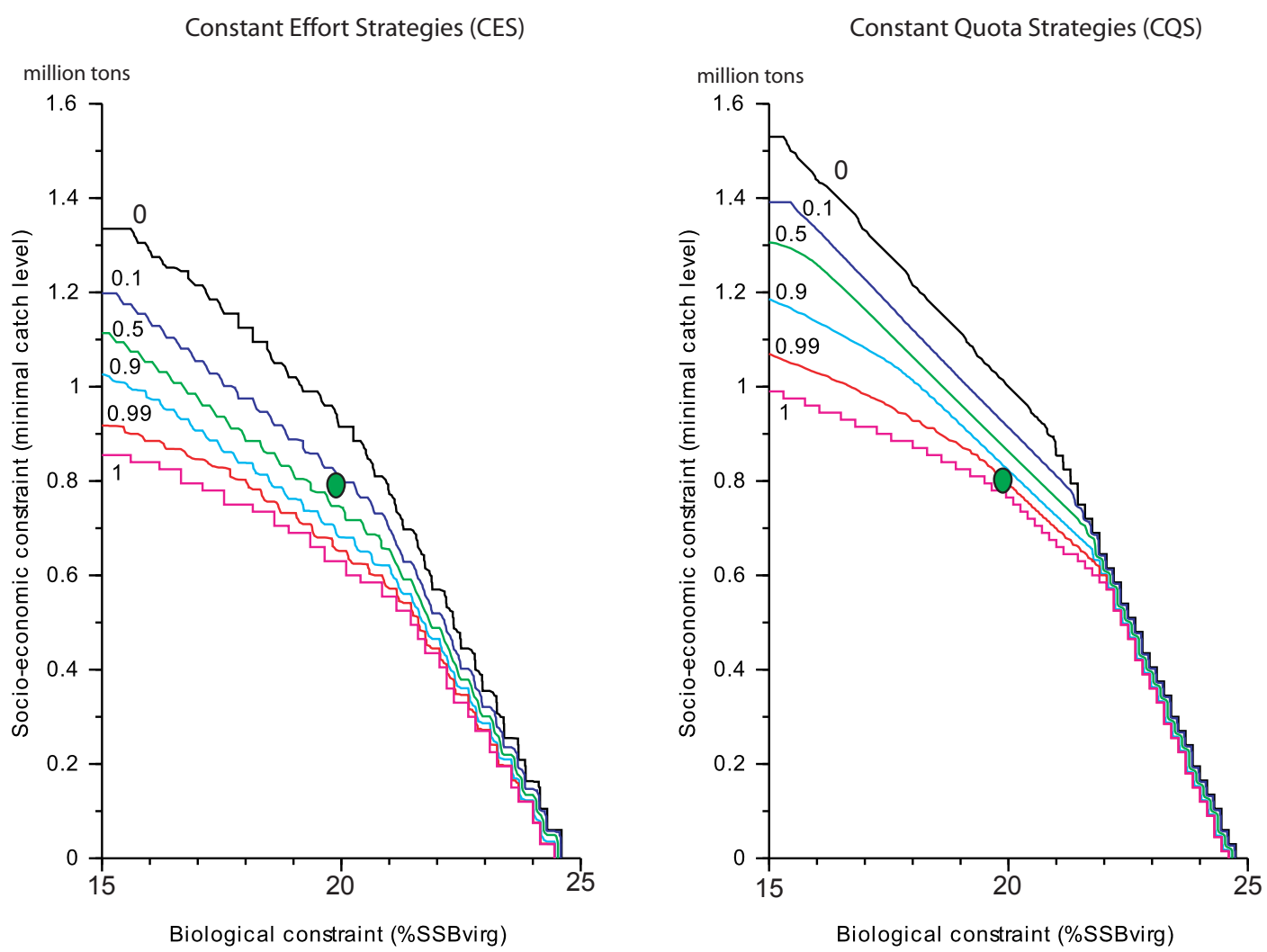

Figure 2: Maximal viability probability of effort and quota strategies (1,000 MonteCarlo simulations). Isoprobability curves are drawn for values $\{0 ; 0.1 ; 0.5 ; 0.9 ; 0.99 ; 1\}$. (Green circle at $(20,0.8)$ corresponding to the sustainability thresholds used for the simulations of Figure 5)

viability value" of each type of strategy as a function of the sustainability thresholds (see eq. 5). 
Ranking management strategies For any given pair of sustainability thresholds, we can rank the alternative management strategies using their viability probability. This allows us to identify the levels of sustainability objectives for which a strategy is likely to perform better than the other from a viability point of view. We determine whether the confidence interval for the viability probability of one type of strategy lies strictly above the confidence interval for the other strategy. Fig. 3 depicts the strategy type with the highest viability probability for each pair $\left(p, y_{\text {min }}\right)$ of biological and economic thresholds. The domain, in terms of sustainability thresholds, where CQS performs strictly better than CES is shaded black. The gray area corresponds to the threshold levels at which the performance of both policy types cannot be statistically distinguished (i.e., confidence intervals intersect). This happens only for viability probabilities close to 1, i.e., for objectives which are easily sustained. The white area corresponds to unsustainable objectives, i.e., thresholds with a viability probability close to zero.

We conclude from this analysis that, for any sustainability objective in the studied range, CQS perform better than CES to sustain catches and biomass levels. ${ }^{22}$

This dominance of quota-based strategies over effort-based strategies is not surprising given the nature of the sustainability constraints considered. To explain this, let us refer to the theoretical result in De Lara and Martinet (2009). In a general framework with an application to fishery, they show that if the dynamics and viability constraints satisfy some monotonicity properties, the maximal viability probability is achieved with the feedback rule which maximizes the escapement level given that the viability constraints are satisfied at the current time. This management strategy can be interpreted as a "precautionary rule." It ensures the achievement of economic objective at the present time while maximizing the probability of economic and ecological objectives being achieved in the future. ${ }^{23}$ When the economic constraint is a minimal

\footnotetext{
${ }^{22}$ This result is robust to the initial state of the fishery. We performed a sensitivity analysis for different initial stocks defined as multiples of the 2002 stock (from $60 \%$ to $150 \%$ ).

${ }^{23}$ Note that, for many fisheries, the International Council for the Exploration of the Sea (ICES) management strategy is based on a rather different strategy: the catch level is set at the highest level compatible with the biological conservation target in the following year, given a confidence interval (precautionary fishing mortality value) (De Lara et al., 2007; Kell et al., 2005). By construction, this strategy leads the stock close to the ecological constraint, with the risk of fishery closure in the shortmedium term if the stock falls below the biological conservation threshold. The strategy maximizing
} 


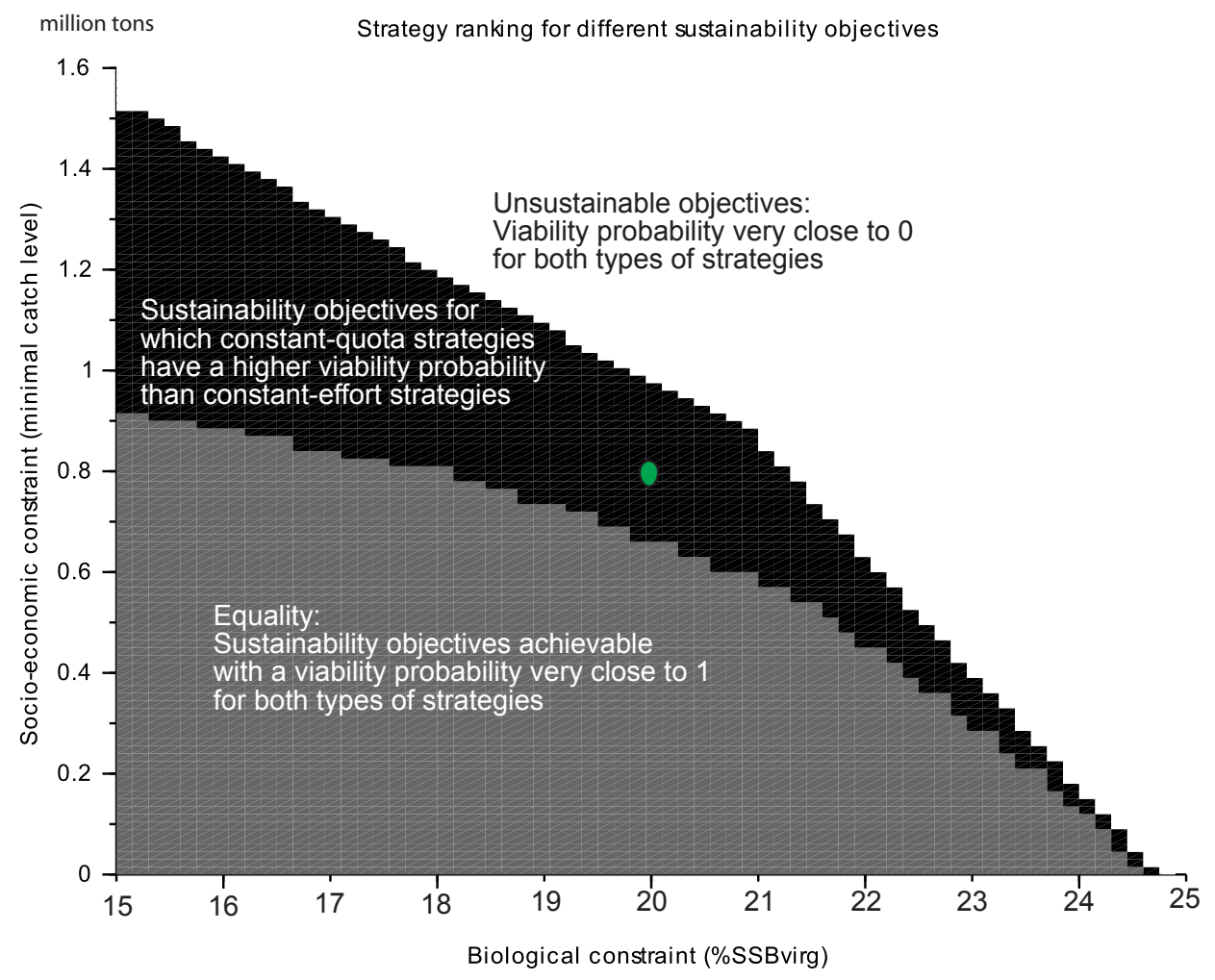

Figure 3: Comparison of CES and CQS policy types (1,000 Monte Carlo's simulations). (Green circle at $(20,0.8)$ corresponding to the sustainability thresholds used for the simulations of Figure 5)

catch level, the rule corresponds to a constant quota at the level of the constraint.

Since the Ricker recruitment function is non-monotonic, with a declining part for large stocks, the model studied here is not monotonic in the sense of De Lara and Martinet (2009). However, the range of SSB modeled belongs to the monotonic part of the Ricker function, which means that the model behaves as if it were monotonic. As one of the viability constraint is a minimal catch level, a constant quota at this level results in the highest viability probability.

The problem of determining which of the effort-based and quota-based strategies dominates in fishery economics is a particular case of the "prices versus quantities" the viability probability is conservative, and results in the resource stock kept as "far" as possible from the biological threshold, given the economic objective. 
debate. A management strategy based on direct control of fishing effort has similar features to tax based management (Danielsson, 2002; Weitzman, 2002). By imposing a maximal fishing effort, one imposes a maximal marginal cost, which interrupts the fishing period before the open access equilibrium. Controlling the effort is similar to imposing a particular landing fee (such as a very high fee starting at some point). Landing fees are a (relatively) better solution to control the (marginal) fishing effort (or cost) but suffer from the drawback of inability to control catch levels. Harvest quotas, on the other hand, have the advantage that they fix the total quantity of fish caught but suffer from the drawback of inability to control the possible excess effort exerted to fish down a stock that is experiencing low recruitment in the fishing period. The related literature shows that, depending on the characteristics of the fishery (i.e., its biological dynamics and economic structure) and the type of uncertainty affecting the model (i.e., whether fish stock and/or economic returns are uncertain), either quota or effort tools may perform better in terms of discounted payoffs (Hannesson and Steinshamn, 1991; Quiggin, 1992; Danielsson, 2002; Jensen and Vestergaard, 2003; Hannesson and Kennedy, 2005; Hansen, 2008). In the stochastic viability framework, the result depends not only on the characteristics of the fishery under study but also on the nature of the sustainability objectives.

Stochastic sustainable production possibility frontiers Fig. 2 presents what was defined in the theoretical analysis of section 3.3 as stochastic sustainable production possibility frontiers. The lines denoting the iso-probabilities represent the tradeoffs between sustainability thresholds $\left(p, y_{\min }\right)$ at various viability probability levels, as characterized by eq. (7). For any given viability probability level, it is necessary to reduce one sustainability threshold to increase another. There is also a trade-off between the sustainability thresholds and confidence in achieving sustainability. Increasing the thresholds results in a decreased viability probability. ${ }^{24}$

These graphical representations are useful to support the social choice of sustainability objectives. They depict the trade-offs between the policy objectives represented by the sustainability thresholds, and the risk of failing to (simultaneously) achieve them. ${ }^{25}$

\footnotetext{
${ }^{24}$ The figure could be made 3 -dimensional, with the viability probability as a function of the thresholds, to emphasize these two different trade-offs.

${ }^{25}$ Note that these trade-offs are between sustainability objectives, not different management strategies (as was the case for the MSE in Fig. 1).
} 
When no SWF can be determined prior to the evaluation of management strategies, and the interest is in sustaining ecological and economic outcomes over time, presenting the trade-offs over all possible sustainability objectives to stakeholders may help to reveal their preferences.

Discussion We can draw some policy-oriented conclusions from the results of our analysis. The important contribution is not the finding of dominance of quota over effort strategies but the representation of the trade-offs between sustainability issues by means of stochastic sustainable production possibility frontiers.

In the early 2000s, biomass levels had been experiencing (for almost a decade) worsening status. As a consequence, our simulation results report non-viable solutions for any threshold pair with $p \geq 25 \%$, either under CQS or CES, whatever the minimum catch threshold.

Over the period analyzed, the TAC was maintained at above 1.3 million tons; however, actual catches did not match this level. Notwithstanding the ecological constraint, Fig. 2 shows that the probability of sustaining the TAC level was not high. Even the best policy among those studied has a low viability probability (around 50\%). This is illustrated in Fig. 4, which compares simulated trajectories for the best CQS and CES for sustainability thresholds $\left(p, y_{\min }\right)=(0,1.3)$, to the historical data (dashed line). The catch level of 1.3 million tons is sustained only in few scenarios (1 for CES, and 3 for CQS).

The main message to the Chilean regulator is that, notwithstanding the choice of instrument, historical quota targets were not sustainable. The information provided by our stochastic sustainable production possibility frontiers could have helped to set lower sustainability targets. For example, Fig. 5 represents simulated trajectories for the best CQS and CES for sustainability thresholds $\left(p, y_{\min }\right)=(0.2,0.8)$, which are achievable with a higher probability than historical levels of quotas (see the green circle at these threshold levels on Fig. 2 and 3). The viability probability for CES is quite low, close to $10 \%$. None of the depicted trajectories are viable. The viability probability for Constant Quota Strategies is very close to one. All the depicted trajectories are viable.

However, these results should be interpreted with caution and political economy considerations should not be underestimated. One of the basic reasons for pursuing the high quota management strategy despite worsening biomass numbers, was that the 

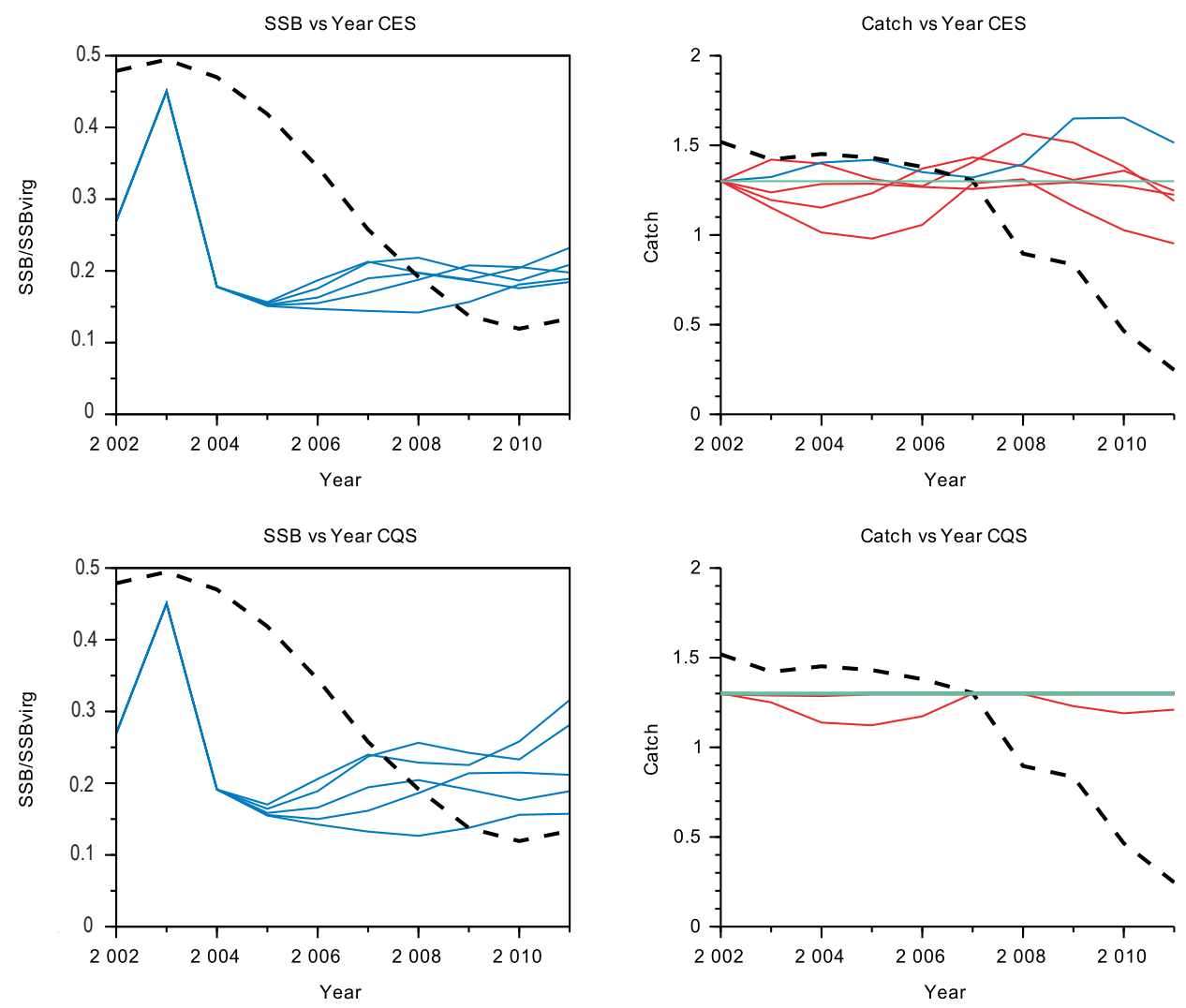

Figure 4: Examples of trajectories under CQS and CES (5 simulations corresponding to 5 different uncertainty scenarios) for sustainability thresholds $\left(p, y_{\min }\right)=(0,1.3)$, compared to historical data (dashed line). The yield threshold is represented by a horizontal (green) line. Catch levels equal the threshold level if constant quota trajectories are feasible. Viable trajectories are in blue. Non-viable trajectories are in red.

Chilean authorities wanted to maintain, for as long as possible, high 'historical fishing presence' of Chilean fleet operating in this fishery ${ }^{26}$ with a view to strengthening Chile's bargaining position in case of future multi-country negotiations about the allocation of country-specific TACs for this common-pool stock. ${ }^{27}$ Time lags were necessary to

\footnotetext{
${ }^{26}$ The drastic 2011 fall in the TAC for the Chilean fleet was related to the change of government in Chile and the (expected) realization that biomass levels (and real catch levels) were inconsistent with previous TAC levels.

${ }^{27}$ Since the early 2000s, the possibility of creating a new (multi-country) Regional Fisheries Management Organization (RFMO) for fishing this straddling stock has been on the table. Initial formal discussions over the establishment of a RFMO related to jack mackerel fishing in the Eastern South
} 

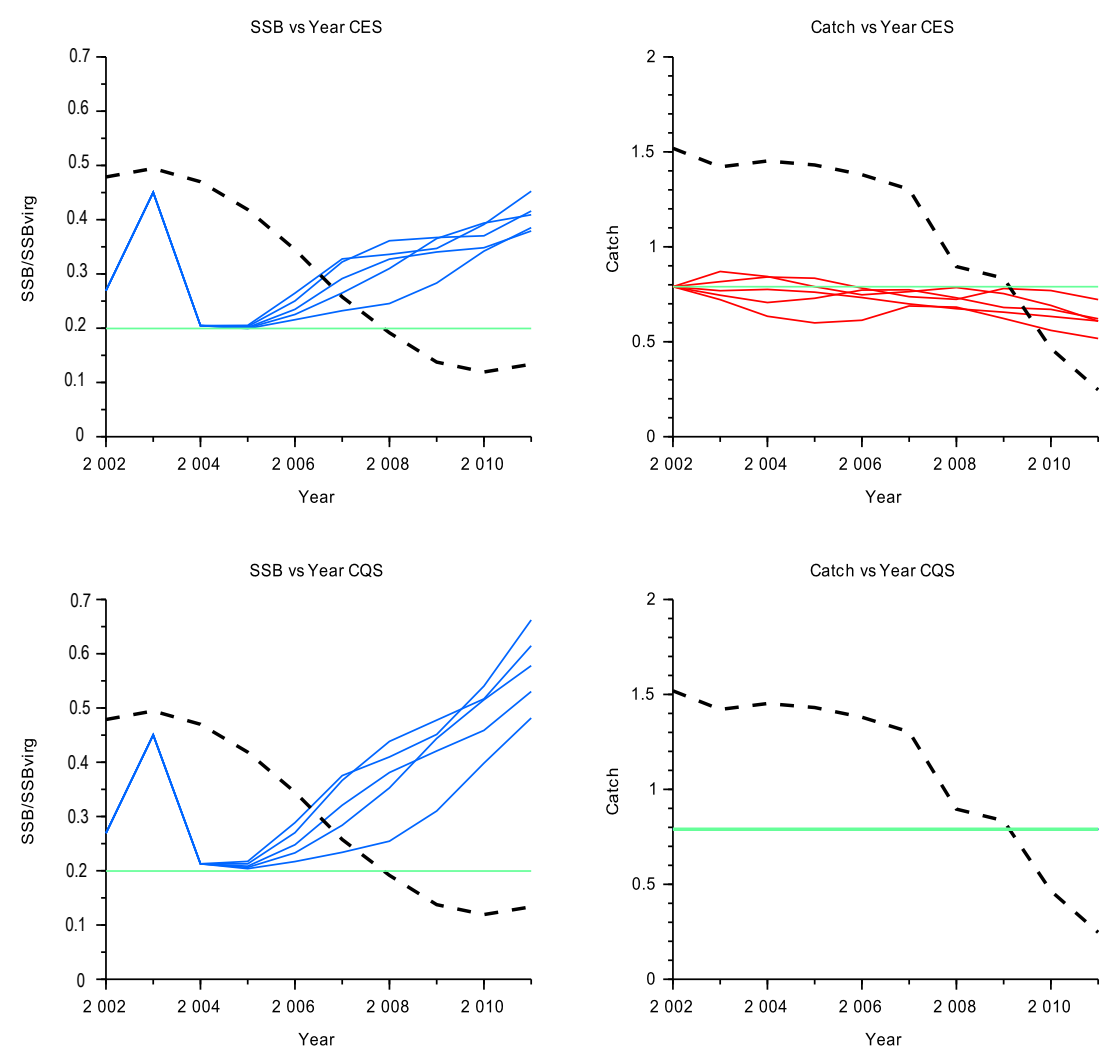

Figure 5: Examples of trajectories under CQS and CES (5 simulations corresponding to 5 different uncertainty scenarios) for sustainability thresholds $\left(p, y_{\min }\right)=(0.2,0.8)$, compared to historical data (dashed line). The biomass and yield thresholds are represented by a horizontal (green) line. Catch levels equal the threshold level for all constant quota trajectories. Viable trajectories are in blue. Non-viable trajectories are in red.

find a more reasonable (multi-country) management solution, and those lags prompted the Chilean authorities' decision to maintain TAC 'as-if constant' (and maintain the resulting 'high' Chilean catches), in response to the common-pool stock issue created by the partial redistribution of the jack mackerel stock into open seas waters beyond Chile's EEZ.

Pacific started in 2006 (involving Chile, Australia and New Zealand). In March 2014, 11 nations (including Chile) had ratified their full membership of this RFMO. Enforcement of formally binding fishing management measures (including allocation of multi-country TACs) started in 2013. (In mid-2012, another 21 nations were debating whether or not to become members of this RFMO). 


\section{Conclusions}

Many problems related to the management of natural resources, such as fisheries, are marked by dynamics and uncertainty. When there are conflicting economic, ecological and social objectives at stake, multicriteria evaluation methods that take account of uncertainty are required to rank potential management strategies. One such method is the Management Strategy Evaluation approach, which characterizes potential management strategies using a set of performance statistics. However, due to the absence of a common metrics for comparing and trading-off conflicting issues, decision-makers are devoid of tools to rank the various management strategies.

To contribute to policy-oriented decision making related to natural resources management problems, we have developed a framework based on stochastic viability. A set of constraints is used to represent the various sustainability objectives of the dynamic ecological economic system. In this framework, management strategies are ranked according to the probability that the resulting intertemporal trajectory satisfies all the objectives over the planning horizon. The viability probability ranks the various management options, defining the strategy that results in the highest viability probability.

This approach acts to complement the traditional economic approach when it is not possible to define a multi-attribute social welfare function. The objective is to maximize the probability of achieving the sustainability constraints. Stochastic viability provides a good way to model decision problems involving several stakeholders interested in sustaining the levels of various indicators. All sustainability dimensions are treated in the same way as constraints representing the minimal rights to be guaranteed to all generations. The decision-maker's preferences are expressed when sustainability thresholds are defined.

The theoretical extension to stochastic viability presented in this paper should help stakeholders to define what should be sustained. Our stochastic viability value function exhibits trade-offs between sustainability objectives (thresholds) and viability probability. Building stochastic sustainable production possibility frontiers allows the set of objectives that can be sustained with some probability to be described.

The proposed stochastic viability methodology is general, and can be applied to a wide range of problems. For example, in this paper we examined the management of a real fishery, using estimated parameters. We applied numerical techniques to 
examine the efficiency of effort- and quota-based management strategies for achieving sustainability objectives, defined as constraints on biological and economic indicators. Monte Carlo simulations were run to estimate the viability probability of each policy with respect to these objectives.

The main contribution of the paper is the development of a framework which provides a common metrics to compare management strategies and to describe the tradeoffs among sustainability objectives, in a way that complements the MSE approach. We suggest that the proposed approach fills the gap between the theoretical economics literature on optimality, and practical decision-making.

Acknowledgments. We acknowledge financial support from the STIC-AmSud program (CNRS, Conicyt-Chile, INRIA and the French Ministry of Foreign Affairs) for the international research framework MIFIMA (Mathematics, Informatics and Fisheries Management). Héctor Ramírez was supported by Conicyt-Chile, under ACT project 10336, FONDECYT 1110888 and BASAL Project (Centro de Modelamiento Matemático, Universidad de Chile), and by project BIONATURE of CIRIC, INRIA-Chile. We thank Claire Nicolas (ENSTAParisTech student), Pauline Dochez (Polytechnique-ParisTech student) and Pedro Gajardo (Universidad Federico Santa Maria, Valparaiso, Chile) for related works, as well as Pablo Koch (Centro de Modelamiento Matemático, Universidad de Chile and INRIA Chile). We are grateful to the participants in various seminars (Rencontres de l'Environnement 2009; CIREQ 2010; UCSB Bren School 2011) and conferences (Diversitas 2009; SURED 2010; WCERE 2010; IIFET 2010), and also Florian Diekert for comments. We also thank the Editor and two anonymous referees. 


\section{Appendix: Chilean jack-mackerel case study: data, parameters and model}

Historical data for the Chilean Jack-Mackerel fishery Table 1 details the historical values of interest for the fishery.

\begin{tabular}{|c|c|c|c|c|c|c|c|}
\hline & (1) & (2) & (3) & (4) & (5) & (6) & (7) \\
\hline & Total Catch & Total Catch DWFNs & TAC & F. Effort Multiplier & Recruits & SSB & Total \\
\hline & Chilean Fleet & (beyond Chilean EEZ) & Chilean Fleet & Chilean Fleet & & & Biomass \\
\hline & (10 $0^{3}$ tons) & ( $10^{3}$ tons $)$ & (10 $0^{3}$ tons) & (implicit $\lambda$ value) & $\left(10^{6}\right.$ individuals $)$ & (10 $0^{3}$ tons) & (10 $0^{3}$ tons) \\
\hline 1980 & 562 & 340 & - & & 21738 & 10564 & 15973 \\
\hline 1981 & 1061 & 438 & - & & 27215 & 10825 & 17114 \\
\hline 1982 & 1495 & 733 & - & & 27652 & 10335 & 17861 \\
\hline 1983 & 865 & 849 & - & & 25645 & 10432 & 17471 \\
\hline 1984 & 1426 & 1060 & - & & 47886 & 10265 & 19017 \\
\hline 1985 & 1457 & 799 & - & & 60875 & 10653 & 20827 \\
\hline 1986 & 1184 & 838 & - & & 28735 & 12190 & 21942 \\
\hline 1987 & 1770 & 863 & - & & 15962 & 13822 & 22698 \\
\hline 1988 & 2138 & 863 & - & & 17644 & 14304 & 22534 \\
\hline 1999 & 2391 & 876 & - & & 23051 & 13652 & 21673 \\
\hline 1990 & 2472 & 872 & - & & 26461 & 12616 & 20751 \\
\hline 1991 & 3020 & 544 & - & & 20834 & 11428 & 19708 \\
\hline 1992 & 3212 & 38 & - & & 16344 & 10377 & 18002 \\
\hline 1993 & 3236 & 0 & - & & 14933 & 9392 & 16140 \\
\hline 1994 & 4041 & 0 & - & & 16942 & 7824 & 14545 \\
\hline 1995 & 4404 & 0 & - & & 18434 & 5775 & 12596 \\
\hline 1996 & 3883 & 0 & - & & 21071 & 4557 & 10378 \\
\hline 1997 & 2917 & 0 & - & & 24326 & 3844 & 9345 \\
\hline 1998 & 1613 & 0 & - & & 21460 & 4070 & 8862 \\
\hline 1999 & 1220 & 0 & 1902 & & 24704 & 4815 & 9622 \\
\hline 2000 & 1235 & 2 & - & & 24298 & 5643 & 10771 \\
\hline 2001 & 1650 & 20 & 1425 & & 20597 & 6312 & 11720 \\
\hline 2002 & 1519 & 76 & 1625 & 0,32 & 12873 & 6848 & 11852 \\
\hline 2003 & 1421 & 158 & 1350 & 0,46 & 8365 & 7073 & 11559 \\
\hline 2004 & 1452 & 295 & 1475 & 0,45 & 6339 & 6722 & 10793 \\
\hline 2005 & 1431 & 244 & 1484 & 0,42 & 3112 & 5988 & 9482 \\
\hline 2006 & 1380 & 363 & 1400 & 0,39 & 5725 & 4934 & 8167 \\
\hline 2007 & 1303 & 439 & 1600 & 0,36 & 7040 & 3685 & 6812 \\
\hline 2008 & 896 & 405 & 1600 & 0,22 & 5808 & 2740 & 5348 \\
\hline 2009 & 835 & 372 & 1400 & 0,17 & 7011 & 1967 & 4364 \\
\hline 2010 & 465 & 240 & 1300 & 0,08 & 7826 & 1706 & 3586 \\
\hline 2011 & 247 & 61 & 315 & 0,03 & 7158 & 1910 & 3418 \\
\hline 2012 & 227 & 40 & 252 & 0,02 & 10892 & 2286 & 4034 \\
\hline 2013 & 242 & 47 & 250 & & & & \\
\hline
\end{tabular}

Table 1: (a) DWFNs: Total annual catch of Distant Water Fishing Nations' Fleets (fishing jack mackerel outside the Chilean EEZ). (b) The Chilean fleet's TAC in column (3) is binding for catches within and beyond the Chilean EEZ. The first year to which TAC was applied in this fishery was 1999; the policy was resumed in 2001 (for more details see Gomez-Lobo et al. (2011)). (c) To deduce the Chilean fleet's (implicit) fishing effort multiplier $(\lambda)$ in column (4), we replaced the annual catch $Y(N, \lambda)$ by its real historical values (column 1) in the Baranov equation (12) and simulated the stock dynamics: starting from the initial vector of abundances at age (for year 2002); we then applied the stock dynamics (equation 11) while considering the deterministic version of the Ricker recruitment function (equation 14), including the deterministic effect of El Niño events (in those years when it occurred, based on the definition in footnote 31). Sources: (1)-(2), (5)-(7): IFOP (2013); (3): Subsecretaría de Pesca (Chilean Fisheries Regulator); (4): authors' own calculations

Biological model We provide details of the model in $\S 4.2$.

The model is age-structured, with a Ricker stock-recruitment function. Abundance 
dynamics are given by

$$
\left\{\begin{array}{l}
N_{a+1}(t+1)=\exp \left(-\left(M_{a}+\lambda(t) F_{a}\right)\right) N_{a}(t), \quad a=1, \ldots, A-2 \\
N_{A}(t+1)=\exp \left(-\left(M_{A-1}+\lambda(t) F_{A-1}\right)\right) N_{A-1}(t)+\exp \left(-\left(M_{A}+\lambda(t) F_{A}\right)\right) N_{A}(t)
\end{array}\right.
$$

where $M_{a}$ is the natural mortality rate of individuals of age $a, F_{a}$ is the mortality rate of individuals of age $a$ due to harvesting between $t$ and $t+1$, supposed to remain constant during year $t$ (the vector $\left(F_{a}\right)_{a=1, \ldots, A}$ is termed the exploitation pattern).

Total annual catches $Y$, measured in million tons, are given by the Baranov catch equation (Quinn and Deriso, 1999, p. 255-256):

$$
Y(N, \lambda)=\sum_{a=1}^{A} \varpi_{a} \frac{\lambda F_{a}}{\lambda F_{a}+M_{a}}\left(1-\exp \left(-\left(M_{a}+\lambda F_{a}\right)\right)\right) N_{a}
$$

where $\left(\varpi_{a}\right)_{a=1, \ldots, A}$ are the weights at age.

The spawning stock biomass (SSB) is given by the expression

$$
\operatorname{SSB}(N):=\sum_{a=1}^{A} \gamma_{a} \varpi_{a} N_{a}
$$

where $\left(\gamma_{a}\right)_{a=1, \ldots, A}$ are the proportions of mature individuals at age $a$ (some may be zero). Annual recruitment is a function of the SSB with a two-year delay, i.e., depending on the spawning stock biomass of two periods earlier: ${ }^{28}$

$$
N_{1}(t+1)=\alpha S S B(N(t-1)) \exp (\beta S S B(N(t-1))+w(t))
$$

where $\{w(t)\}$ is a random process reflecting the impact of climatic factors on the stock recruitment relationship (see below).

We use the parameter estimation proposed in Yepes (2004), which relies on official data from the Instituto de Fomento Pesquero (IFOP). ${ }^{29}$ Parameters of the Ricker recruitment function at expression (14) were estimated using linear time-series analysis. The estimated parameters are $\alpha=e^{2.39}$ and $\beta=-2.2 \cdot 10^{-7}$ (see Yepes, 2004, p. 56). The values for parameters $M_{a}$ and $F_{a}$ are taken from IFOP's official model for this

\footnotetext{
${ }^{28}$ This 2-year delayed effect is due to the biological growth dynamics of the species.

${ }^{29}$ Subsecretaria de Pesca, Valparaíso - Chile: Cuota Global de Captura para la Pesquería del Recurso Jurel, Año 2001 (SUBPESCA, 2000); and Instituto de Fomento Pesquero, Valparaíso - Chile: Informe Complementario Investigación CTP Jurel, 2003: Indicadores de Reclutamiento (IFOP, 2003).
} 
fishery, so that $M_{a}$ is equal to 0.23 for all $a$ and $F_{a}$ is equal to the vector of averages values of $F_{a}$ during 2001-2002. ${ }^{30}$

Stochastic model Following the statistical analysis in Yepes (2004), we simulate El Niño uncertain cycles using a sinusoidal function with random shocks. ${ }^{31}$ The random process $w(t)$ supposed to capture the effects of the El Niño phenomenon has a periodic part and an error term, $w(t)=-0.12 \times \operatorname{niño}(t)+\epsilon(t)$, where

- the estimated error terms $\{\epsilon(t)\}$ correspond to $\epsilon(t)=0.71 \epsilon(t-1)-0.65 \epsilon(t-$ $2)+\mu(t)$, where $\{\mu(t)\}$ is a sequence of i.i.d. random variables with Normal distribution $\mathcal{N}(0 ; 0.18)$,

- $\operatorname{niño}(t)=\mathbf{1}_{\{-1.2 \sin (18.19+2 \pi(t-1951) / 3.17)>0.5\}}$ is a dummy (0 or 1) variable reflecting the presence of El Niño phenomenon.

Simulation process From a theoretical point of view, it is possible to determine the strategy that maximizes the viability probability by solving the dynamic programming equation characterizing the viability problem (De Lara et al., 2006). It is possible to obtain a closed-form solution for some problems (De Lara and Martinet, 2009). Determining optimal strategies in dynamic optimization problems under uncertainty is not easy. Optimization in the stochastic viability framework is not exceptional. In particular, the curse of dimensionality can be a serious obstacle to the computation of optimal viability strategies.

From a practical point of view, it is possible to estimate the viability probability of any given strategy by means of Monte Carlo simulations. A random generator is used to

\footnotetext{
${ }^{30}$ See Subsecretaria de Pesca, Valparaíso - Chile, SUBPESCA (2006) Pre Informe Final. Investigación Evaluation y CTP Jurel 2006.

${ }^{31}$ Based on Chilean marine biologists advice, Yepes (2004) calculates the occurrence of the El Niño phenomenon based on National Oceanic and Atmospheric Administration (NOAA) data on sea surface temperatures measured at the region known as Niño 3.4 (120W-170W, 5N-5S). NOAA computes the Oceanic El Niño Index (ONI) as the difference in current sea surface temperature (SST) with respect to the historical average SST for the period 1971-2000. We then computed a three-month moving average series, on the basis that $\mathrm{El} \mathrm{Niño} \mathrm{occurs} \mathrm{if} \mathrm{this} \mathrm{average} \mathrm{is} \mathrm{greater} \mathrm{than} 0.5^{\circ} \mathrm{C}$ for five consecutive months (see the expression of niño $(t)$ ). The ONI is modeled via a sinusoidal function whose parameters are estimated using a non-linear iterative algorithm (Yepes, 2004, p. 64), to represent the different cycles of El Niño.
} 
produce scenarios following the distribution $\mathbb{P}$. For each scenario, a given management strategy is applied. If, for the corresponding trajectory, all the viability constraints in (4) are respected in each time period over the whole planning horizon, the scenario is viable for the applied management strategy. When the number of scenarios tested is large, the frequency of viable scenarios can be used as an approximation of the viability probability.

\section{References}

R.T. Barber and F.P. Chavez. Biological consequences of El Niño. Science, 222(4629): 1203-1210, 1983.

M. Begon and M. Mortimer. Population Ecology; A unified study of animals and plants. Blackwell Scientific Publications, 1986.

D.S. Butterworth and M.O. Bergh. The development of a management procedure for the South African anchovy resource. In J.J. Hunt S.J. Smith and D. Rivard, editors, Risk Evaluation and Biological Reference Points for Fisheries Management, pages 83-99. Canadian Special Publication of Fisheries and Aquatic Science 120, National Research Council and Department of Fisheries and Oceans, Ottawa, 1997.

D.S. Butterworth, K.L. Cochrane, and J.A.A. De Oliveira. Management procedures: a better way to manage fisheries? The South African experience. In D. D. Huppert E. K. Pikitch and M. P. Sissenwine, editors, Global Trends: Fisheries Management, pages 83-90. American Fisheries Society Symposium 20, 1997.

A. Charles. Living with uncertainty in fisheries: analytical methods, management priorities and the Canadian groundfishery experience. Fisheries Research, 37:37-50, 1998.

C. W. Clark. Mathematical Bioeconomics. Wiley, New York, second edition, 1990.

C.W. Clark and G.P. Kirkwood. On uncertainty renewable resource stocks: Optimal harvest policy and the value of stock surveys. Journal of Environmental Economics and Management, 13:235-244, 1986. 
K. L. Cochrane. Reconciling sustainability, economic efficiency and equity in fisheries: the one that got away? Fish and Fisheries, 1:3-21, 2000.

C.J. Costello, R.M. Adams, and S. Polasky. The value of El Niño forecasts in the management of salmon: A stochastic dynamic assessment. American Journal of Agricultural Economics, 80:765-777, 1998.

J.-M. Da-Rocha, L. Nøstbakken, and M. Pérez. Pulse fishing and stock uncertainty. Environmental and Resource Economics, forthcoming, 2013.

A. Danielsson. Efficiency of catch and effort quotas in the presence of risk. Journal of Environmental Economics and Management, 43:20-33, 2002.

M. De Lara and L. Doyen. Sustainable Management of Natural Resources. Mathematical Models and Methods. Springer-Verlag, Berlin, 2008.

M. De Lara and V. Martinet. Multi-criteria dynamic decision under uncertainty: A stochastic viability analysis and an application to sustainable fishery management. Mathematical Biosciences, 217(2):118-124, 2009.

M. De Lara, L. Doyen, T. Guilbaud, and M.-J. Rochet. Monotonicity properties for the viable control of discrete time systems. Systems and Control Letters, 56(4):296-302, 2006.

M. De Lara, L. Doyen, T. Guilbaud, and M.-J. Rochet. Is a management framework based on spawning-stock biomass indicators sustainable? A viability approach. ICES Journal of Marine Science, 64(4):761-767, 2007.

J. A. A. De Oliveira and D. S. Butterworth. Developing and refining a joint management procedure for the multispecies South African pelagic fisheries. ICES Journal of Marine Science, 61:1432-1442, 2004.

L. Doyen, O. Thébaud, C. Béné, V. Martinet, S. Gourguet, M. Bertignac, S. Fifas, and F. Blanchard. A stochastic viability approach to ecosystem-based fisheries management. Ecological Economics, 75:32-42, 2012.

W.J. Fletcher. The application of qualitative risk assessment methodology to prioritize issues for fisheries management. ICES Journal of Marine Science, 62:1576-1587, 2005 . 
H. F. Geromont, J. A. A. De Oliveira, S. J. Johnston, and C. L. Cunningham. Development and application of management procedures for fisheries in Southern Africa. ICES Jounal of Marine Science, 56:952-966, 1999.

A. Gomez-Lobo, J. Pe na Torres, and P. Barria. ITQs in Chile: Measuring the economic benefits of reform. Environmental and Resource Economics, 48(4):651-678, 2011.

R. Hannesson and J. Kennedy. Landing fees versus fish quotas. Land Economics, 81(4): 518-529, 2005.

R. Hannesson and S.I. Steinshamn. How to set catch quotas: Constant effort or constant catch? Journal of Environmental Economics and Management, 20:71-91, 1991.

L.G. Hansen. Prices versus Quantities in fisheries models: Comment. Land Economics, 84(4):708-711, 2008.

R. Hilborn. Defining success in fisheries and conflicts in objectives. Marine Policy, 31: 153-158, 2007.

IFOP. Investigación evaluación de stock y CTP Jurel 2006, 2006. Informe Final Proyecto BIP 30033881-0, Marzo, Valparaíso, 71 pages.

IFOP. Investigación del estatus y posibilidades de explotación biológicamente sustentables en jurel, año 2014, 2013. Informe Final Proyecto 2.1, Octubre 2013, Subsecretería de Economía, 145 pages.

F. Jensen and N. Vestergaard. Prices versus Quantities in Fisheries Models. Land Economics, 79(3):415-425, 2003.

L. T. Kell, G. M. Pilling, G. P. Kirkwood, M. Pastoors, B. Mesnil, K. Korsbrekke, P. Abaunza, R. Aps, A. Biseau, P. Kunzlik, C. Needle, B. A. Roel, and C. UlrichRescan. An evaluation of the implicit management procedure used for some ICES roundfish stocks. ICES Journal of Marine Science, 62:750-759, 2005.

V. Martinet. A characterization of sustainability with indicators. Journal of Environmental Economics and Management, 61:183-197, 2011.

V. Martinet. Economic Theory and Sustainable Development: What can we preserve for future generations? Routledge, London, 2012. 
B. McCough, A.J. Plantinga, and C. Costello. Optimally managing a stochastic renewable resource under general economic conditions. The B.E. Journal of Economic Analysis \&3 Policy, 9(1):Article 56, 2009.

L. Nøstbakken. Regime switching in a fishery with stochatic stock and price. Journal of Environmental Economics and Management, 51:231-241, 2006.

L. Nøstbakken. Stochastic modelling of the North Sea Herring fishery under alternative management regimes. Marine Resources Economics, 22:63-84, 2008.

L. Nøstbakken and J. Conrad. Uncertainty in bioeconomic modelling. In Handbook on Operations Research in Natural Resources, chapter 12, pages 217-235. Kluwer, 2007.

J. Peña Torres, C. Agostini, and S. Vergara. Fish stock endogeneity in the harvest function: El niño effects on the Chilean Jack-Mackerel fishery. Revista de Análisis Económico, 22(2):75-99, 2007.

J. Peña Torres, J. Dresdner, and F. Vasquez. El niño and fishing location decisions: The Chilean straddling Jack-Mackerel stock. submitted, 2014.

E.K. Pikkitch, C. Santora, E.A. Babcock, A. Bakun, R. Bonfil, D.O. Conover, and et al P. Dayton. Ecosystem based fishery management. Science, 305:346-347, 2004.

J. Quiggin. How to set catch quotas: A note on the superiority of constant effort rules. Journal of Environmental Economics and Management, 22:199-203, 1992.

T. J. Quinn and R. B. Deriso. Quantitative Fish Dynamics. Biological Resource Management Series. Oxford University Press, New York, 1999. 542 pp.

W. Reed. Optimal escapement levels in stochastic and deterministic harvesting models. Journal of Environmental Economics and Management, 6:350-363, 1979.

K. J. Sainsbury, A. E. Punt, and A. D. M. Smith. Design of operational management strategies for achieving fishery ecosystem objectives. ICES Journal of Marine Science, 57:731-741, 2000.

G. Sethi, C. Costello, A. Fisher, M. Hanemann, and L. Karp. Fishery management under multiple uncertainty. Journal of Environmental Economics and Management, 50:300-318, 2005. 
H. Simon. A behavioral model of rational choice. In Models of Man, Social and Rational: Mathematical Essays on Rational Human Behavior in a Social Setting. Wiley, New York, 1957.

R. Singh, Q. Weninger, and M. Doyle. Fisheries management with stock uncertainty and costly capital adjustment. Journal of Environmental Economics and Management, 52:582-599, 2006.

A.D.M. Smith, E.J. Fulton, A.J. Hobday, D.C. Smith, and P. Shoulder. Scientific tools to support the practical implementation of ecosystem-based fisheries management. ICES Journal of Marine Science, 64:633-639, 2007.

R. Solow. Intergenerational equity and exhaustible resources. Review of Economic Studies, 41:29-45, 1974. Symposium on the economics of exhaustible resources.

N. Stern. The Economics of Climate Change. Cambridge University Press, 2006.

SUBPESCA. Cuota global anual de captura de jurel, año 2005. Technical report, Subsecretaria de Pesca, Valparaíso, Octubre 2004. Informe Tecnico (R. Pesq.) numero $79 / 2004$.

O. Tahvonen. Economics of harvesting age-structured fish populations. Journal of Environmental Economics and Management, 58(3):281 - 299, 2009.

M. Weitzman. Landing fees vs harvest quotas with uncertain fish stocks. Journal of Environmental Economics and Management, 43:325-338, 2002.

M. Yepes. Dinámica poblacional del jurel: Reclutamiento asociado a factores ambientales y sus efectos sobre la captura. Thesis for joint Master degree in Economics, Georgetown University/ILADES, and Faculty of Economics and Business, Universidad Alberto Hurtado, Santiago, Chile, 2004. 